\title{
$\begin{array}{lllllll}\mathbf{R} & \mathbf{E} & \mathrm{S} & \mathbf{E} & \tilde{\mathbf{N}} & \mathbf{A}\end{array}$
}

\section{Zarazúa, Ulises, 2006, Crónicas marginales. Cinco espejos para reconstruir la ciudad, Universidad Autónoma Metropolitana-Gobierno del Distrito Federal.}

P ara Lacán es importante el ejercicio cotidiano de la mirada. Cómo realmente uno percibe su entorno a través del proceso de la mirada. Cómo los otros nos perciben a través de esa misma reciprocidad. Sabemos que ver y mirar son dos verbos similares pero con muy distinto significado. Para Lacán lo más importante no es el proceso del ojo que ve, observa, sino la interiorización, convertida en mirada, de ese mismo proceso al cual el yo le da una interpretación particular. Como en el cuento de Edgar Allan Poe, El corazón delator, en el que el psicótico personaje llega a desesperarse por el ojo gris, de buitre, del viejo que era su vecino y, sobre todo, por la forma como éste fijaba la mirada muerta de ese ojo, en él, atravesándole el alma.

El ejercicio de deambular, deslizando la mirada con detenimiento en lo que llama la atención del ojo, es lo que Ulises Zarazúa realiza en las calles y la cotidianidad de Guadalajara, y que plasma en cinco crónicas recopiladas en el libro titulado Crónicas marginales. Cinco espejospara reconstruir la ciudad, editado por la Universidad Autónoma Metropolitana (UAM) y el Gobierno del Distrito Federal, el cual fue ganador del concurso internacional de crónica urbana "Salvador Novo" en 2004.

Con soltura, sin inhibiciones, casi con cinismo y desparpajo, Zarazúa va pintando un mosaico de su ciudad, entrañable, pero sin que esto impida verter sobre ella diferentes opiniones vitriólicas. El libro está escrito de una forma sencilla y directa, motivo por el cual su lectura se asimila de inmediato. Tiene la virtud, porque opino que debe ser considerado así en estos tiempos, de ir matizado de humor; así, demuestra que la seriedad y la solemnidad con que a veces se contempla la vida no deben ser plasmadas, necesariamente, de igual manera en el quehacer creativo. Me parece que ese elemento provoca la amenidad del discurso. Como las descripciones fueron elaboradas a partir de la ciudad de Guadalajara, es obvio que a los vecinos de dicha ciudad les será fácil identificarse en los textos de Zarazúa, ya que compartir dicho espacio va generando la memoria colectiva y no serán pocos los que se reconozcan como actores dentro de la fluidez de las crónicas, en virtud de que en éstas el autor explora diferentes temáticas, como la actividad comercial en los mercados, las manifestaciones gay, las cavilaciones de un peatón, la cotidianidad que transcurre dentro los muros de la prisión o lo que acontece principalmente el fin de semana en un famoso parque. Así, las crónicas son las siguientes: 1. El baratillo o su majestad la multitud. 2. La marcha gay o de cómo la mojiganga del cardenal fue expulsada de entre las locas. 3. Divagaciones de un peatón. 4. Puente Grande. 5. Parque Rubén Dario.

Por razones particulares, de gusto, me quedo con las dos primeras crónicas, las que califico como excelentes y muy bien logradas; pero ya sabemos que toda elección pasa por el tamiz del gusto individual y en consecuencia otros lectores podrán elegir otras 
como favoritas. En el primer texto se aborda el comercio marginal que se lleva a cabo en el mercado conocido como el Baratillo: "Inicio por el principio. El principio que inicia y comienza bullicioso: si todos los caminos conducen a Roma, todas las rutas de Guadalajara conducen al baratillo...en Calzada del Obrero y Puerto Melaque...estamos en el oriente profundo de la urbe tapatía”, escribe Zarazúa.

Y, como moderno Virgilio, nos toma de la mano y se torna nuestro guía para sumergirnos en un mundo matizado por el bombardeo hacia nuestros sentidos. Comienza describiendo olores de tan diversa índole, que no es posible dejar en el olvido al personaje de Patrick Süskind en Elperfume; dicho personaje, sin duda, se hubiera dado un festín husmeando el Baratillo por todas partes.

"Un ciego podría reconstruir la geografía del baratillo utilizando sólo su olfato”, escribe Zarazúa, quien hace que el lector asista al viejo ritual popular de compra-venta e intercambio, matizado ahora por el marketing de la globalización y la piratería: los vendedores usan calculadoras, y se ve que gran parte de la importancia de la mercancía radica en el trato comercial a partir de los animales: chivos, cabras, conejos...los que serán sacrificados en pro de conservar la tradición culinaria de los tapatíos.

Si se sigue la pauta descriptiva de Zarazúa se encontrará una especie de mercado surrealista, donde incluso se llevan a cabo peleas de gallos clandestinas; con ojo avizor las autoridades, en pleno uso de sus facultades legales, apresan a los instigadores del desorden, alegando que las peleas de gallos, y cualquier tipo de juego de azar, están prohibidas. Apartan a los infractores de la ley y después de tener una plática "constructiva" con ellos, los infractores dejan en las manos de los guardianes de la justicia el dinero de las apuestas, luego, las cosas quedan en calma.

En el Baratillo parece ser que el tráfico con especies silvestres y mascotas exóticas está siempre en su apogeo.
Lo mismo que lo relacionado con los perros, porque en los puestos callejeros del lugar se pueden encontrar un sinfín de razas auténticas y algunas "disfrazadas" para aparentar lo que no son.

Sin duda, la actividad del Baratillo se convierte en un auténtico fenómeno de masas, digno de experimentar dejando por un lado los prejuicios y haciéndose a la idea, aunque el ego de cada uno se resienta, de que, al final de cuentas, puede existir la división de los estratos sociales, pero la sustancia humana es la misma en todas partes.

En la crónica sobre la marcha gay y de travestis Zarazúa cuenta que el punto de concentración se llevó a cabo un sábado a las cuatro de la tarde en las calles de Hidalgo y Chapultepec, corazón de la Zona Rosa tapatía.

Bourdieu alude en su obra La historia del sexo que, a partir de la explosión económica de la revolución industrial, el sexo, dentro del contexto capitalista, se fue convirtiendo en una especie de tabú cuya mención se soslaya y se reglamenta para que en los círculos sociales se pueda hablar, o mejor no hablar, con decoro sobre él. Y aquí, es pertinente preguntarse en qué punto sobre este aspecto está cada uno de nosotros. ¿Cómo abordamos el sexo? ¿Con naturalidad, con prejuicios, con tabúes, con inhibiciones, soslayándolo, manifestando una doble moral que de necesidad deriva en hipocresía?

Tal vez por eso, dentro de la marcha gay, la exposición de los cuerpos al aire libre, o mejor dicho, de bustos y glúteos, de hombres y mujeres, homosexuales todos, portando orgullosamente banderines con los colores del arco iris, que es la insignia que los identifica, viajando a bordo de los carros alegóricos, llama la atención de los transeúntes, quienes dedican buena parte de su tiempo a reír, a burlarse, a desear lo que sus ojos contemplan, que no deja de ser un gran carnaval saturado de colores, listones, cantos y lentejuelas. Que no deja de ser un acto de denuncia en contra de la opresión ejercida por las autoridades, mediante el cual 
se pide que se les dé paso legal a las sociedades de convivencia homosexuales, “...que no son matrimonio, pero da derechos". Y verter también el descontento en contra de la posición de la Iglesia, representada aquí concretamente por el arzobispo de Guadalajara, Juan Sandoval Iñiguez, por no aceptar la existencia de los homosexuales y hacer manifiesta, las veces que puede, la discriminación a tal preferencia sexual. A eso obedece la razón de llevar una mojiganga de tres metros de altura que representa al prelado en cuestión y “...una franja de tela al pecho dice: "Miss Discriminación Gay 2004...". La marcha concluye finalmente en la plaza de La Liberación con un festival artístico al cual se integran varios de los espectadores, y se da la intervención de varios oradores a favor de la libertad de las tendencias sexuales.

Lo interesante de esta crónica es observar cómo en una ciudad que es considerada como la segunda más importante en el país, tiene lugar una marcha que, precisamente en la libertad de manifestación, evidencia lo limitada que está en relación con la tolerancia y la diversidad sexual.
Zarazúa concluye así su participación como observador del evento al decir:

Volteo lo más arriba que puedo y miro al sol escondiéndose bajo una nube que presagia lluvia: los rayos solares, por obra y gracia de la refracción lumínica, crean un extraño y atípico arco iris. Entonces, un hombre que también observa el capricho meteorológico me dice, la mirada encendida y la voz temblorosa, como si estuviera recibiendo un fax del cielo:

—Dios está de nuestra parte; es de los nuestros...

Para concluir, opino que las Crónicas Marginales de Ulises Zarazúa pueden no sólo dar un momento grato al lector, sino también, lo pueden llevar a reflexionar sobre varios aspectos de actualidad, ya que trascienden en sí el espacio urbano de Guadalajara y lo narrado puede pasar en cualquier ciudad.

Gabriel Hernández García

CESMECA-UNICACH 